\title{
Progression to insulin-requiring diabetes in seronegative prediabetic subjects: the role of two HLA-DQ high-risk haplotypes
}

\author{
M. Pietropaolo ${ }^{1}$, D.J. Becker ${ }^{1}$, R.E. LaPorte ${ }^{2}$, J.S. Dorman ${ }^{2}$, S. Riboni ${ }^{1}$, W. A. Rudert ${ }^{1}$, S. Mazumdar ${ }^{3}$, M. Trucco ${ }^{1}$ \\ ${ }^{1}$ Division of Immunogenetics, Diabetes Institute, Rangos Research Center, Children's Hospital of Pittsburgh, University of \\ Pittsburgh School of Medicine, Pittsburgh, Pennsylvania, USA \\ ${ }^{2}$ Department of Epidemiology, Graduate School of Public Health, University of Pittsburgh, Pittsburgh, Pennsylvania, USA \\ ${ }^{3}$ Department of Biostatistics, Graduate School of Public Health, University of Pittsburgh, Pittsburgh, Pennsylvania, USA
}

\section{Abstract}

Aims/hypothesis. Most Caucasians with Type I (insulin-dependent) diabetes mellitus develop an autoimmune form of diabetes known as Type IA diabetes, based on the presence of humoral responses to islet autoantigens. Alleles at the $H L A$ locus account for the strongest susceptibility to this form of diabetes, which requires insulin therapy. Because a number of patients who develop insulin-requiring diabetes are islet autoantibody negative, the $H L A$ class II haplotypes, $D Q A 1 * 0501-D Q B 1 * 0201$ and $D Q A 1 * 0301$ $D Q B 1 * 0302$, were evaluated to assess whether they are an independent risk factor for progression to insulin requirement in first-degree relatives of Type I diabetic patients.

Methods. Both HLA-DQ genotyping and islet cell autoantibody assessment (insulin, GAD65, IA-2 autoantibodies and cytoplasmic islet cell antibodies) were evaluated prospectively in 74 relatives of Type I diabetic patients who developed diabetes treated with insulin (prediabetics) and in 426 control subjects who did not develop insulin-requiring diabetes. Based on the presence of $D Q A 1 * 0501-D Q B 1 * 0201$ and/or $D Q A 1 * 0301-D Q B 1 * 0302$, the number of $H L A-D Q$ high-risk haplotypes was assigned as 0,1 or 2 .

Results. A higher prevalence of $2 H L A-D Q$ high-risk haplotypes was present in seronegative prediabetic subjects as compared to non-diabetic autoantibody negative first-degree relatives $(33.3 \%$ vs $10.1 \%$ respectively; $p<0.05)$. Moreover, in seronegative relatives who developed insulin-requiring diabetes, the presence of $2 H L A-D Q$ high-risk haplotypes conferred an increased cumulative risk of developing insulin requirement of $27 \%$ at 12.5 years of follow-up, compared to a risk of $6 \%$ for non-diabetic relatives who were antibody-negative and had 0 or $1 H L A$ $D Q$ high-risk haplotypes ( $\log$ rank $p=0.01)$.

Conclusion/interpretation. These data provide evidence for a phenotype, which is associated with the absence of conventional islet autoantibodies at initial screening, while usually remaining seronegative, and the presence of $2 H L A-D Q$ high-risk haplotypes with progression to clinical Type I diabetes after a prolonged follow-up. Given the fact that in humans the highest risk-conferring locus associated and linked to the disease is the HLA cluster, and that $H L A-D Q$ molecules play a key role in the development of autoimmune diabetes, our observations imply that as yet unidentified immunologic abnormalities could well exist in seronegative relatives at risk of developing clinical diabetes and carrying $2 H L A$ $D Q$ high-risk haplotypes. [Diabetologia (2002) 45: 66-76]

Keywords Seronegative insulin-requiring diabetes, 2 $H L A-D Q$ high-risk haplotypes, islet cell autoimmunity, autoantibodies.
Received: 29 May 2001 and in revised form: 28 September 2001

Corresponding author: M. Pietropaolo, M. D., Division of Immunogenetics, Diabetes Institute, Rangos Research Center, Children's Hospital of Pittsburgh, University of Pittsburgh School of Medicine, 3460 Fifth Avenue, Pittsburgh, PA 15213, USA, e-mail: pietroma+@pitt.edu

Abbreviations: CHP, Children's Hospital of Pittsburgh
The presence of circulating autoantibodies reacting with a variety of islet antigens is essential for the correct classification and prediction of Type I (insulindependent) diabetes mellitus $[1,2]$. However, it has been shown that a number of diabetic patients without these antibodies have clinical features of Type I diabetes [3, 4]. In particular, African American and 
Hispanic American Type I diabetic children have a lower prevalence of anti-islet autoantibodies than Caucasian children [3, 4].

According to a recent report of the American Diabetes Association Expert Committee on the Diagnosis and Classification of Diabetes Mellitus [5], the lack of evidence of islet cell autoimmunity, assessed by the measurement of conventional humoral autoantibodies (GAD, IA-2, insulin and cytoplasmic ICA), is usually defined as idiopathic or Type IB diabetes. The classification of diabetes into Type IA and Type IB diabetes is not always easy and could even be misleading [6, 7]. In a series of 148 patients diagnosed as Type I diabetic [8], all the patients without circulating autoantibodies $-10 \%$ - had T-cell evidence of autoimmunity. Similar findings have been reported in atypical diabetes [9]. Therefore, despite the American Diabetes Association effort to further improve the current classification of diabetes, there is still active discussion on the criteria to be considered as the most appropriate for classifying diabetes.

In Caucasians, the HLA class II haplotypes that confer the highest susceptibility for Type I diabetes are $D Q A 1 * 0501-D Q B 1 * 0201$ (associated with $D R 3$ ), and $D Q A 1 * 0301-D Q B 1 * 0302$ (associated with $D R 4$ ) [10-16]. Direct in vivo evidence implicating the $H L A-D Q$ molecules in the development of autoimmune diabetes has been provided by experiments involving a humanized transgenic mouse model of spontaneous diabetes [17]. Specifically, inbred mice the class II genes of which were replaced by $D Q A 1 * 0301$ and $D Q B 1 * 0302$ genes developed spontaneous autoimmune diabetes.

Because there is strong evidence indicating that inherited susceptibility to Type I diabetes is primarily associated and linked with genes of the major histocompatibility complex (MHC) [16, 18-23], we evaluated whether the presence of $H L A-D Q$ high-risk haplotypes, defined as $D Q A 1 * 0501-D Q B 1 * 0201$ and $D Q A 1 * 0301-D Q B 1 * 0302$ [24], can identify and predict insulin requirement in first-degree relatives of diabetic patients without evident signs of islet cell autoimmunity. These patients were followed longitudinally.

Our long-term follow-up allowed us to identify seronegative first-degree relatives carrying $2 H L A-D Q$ high-risk haplotypes who progressed to insulin requirement over time. This probably represents a subgroup of autoantibody negative patients described at the onset of Type I diabetes [4, 25-27]. Of note, the distribution of $H L A$ genotypes in Type I newly diagnosed diabetic children with Type IB diabetes (by definition seronegative patients), seems to resemble Type IA diabetic patients more than the background population [7]. Our conclusion is not intended at increasing sensitivity of combined assays by the addition of $H L A-D Q$ genotypes, but it rather suggests that additional immunologic markers could well be present in seronegative prediabetes and in Type I diabetic patients with susceptible $M H C$ haplotypes.

\section{Subjects and methods}

Study design. The Children's Hospital of Pittsburgh (CHP) cohort includes 6711 first-degree relatives of children and adolescents with Type I diabetes who have been recruited since 1979 and followed for up to 20 years [28]. A hospital-based registry at the hospital, which identifies all children ( $\leq 17 \mathrm{yr}$. of age) who were diagnosed or seen within one year of diagnosis since $1^{\text {st }}$ January 1950 was used to identify study subjects [28].

The CHP registry is based on a population-based registry in Allegheny County. This was developed through retrospective record review of all hospitals in the county to identify all children who fulfill standard criteria [28]. There is a very high degree of overlap between these two registries. Over $70 \%$ of all children diagnosed in the county were seen at onset at the Children's Hospital diabetes centre. The descriptive epidemiology of the two registries is virtually identical. Therefore, the Children's registry is representative of the population-based Allegheny County registry [28]. All first-degree relatives of the patients seen at CHP were recruited into the study.

Subjects. A subgroup of 507 of 6711 non-diabetic first-degree relatives of diabetic probands from the CHP registry was evaluated. This subgroup was selected on the basis of the availability of DNA specimens, the collection of which was begun in 1988. The first available blood sample of all relatives was screened for glucose levels and cytoplasmic islet cell antibodies (ICA) using a rat pancreas substrate. There was sufficient serum from 500 of the 507 subjects to measure autoantibodies to GAD65, IA-2 and insulin. These 500 subjects were thus included in further analyses. The subgroup of 500 first-degree relatives included in the present study was selected on the basis of the availability of DNA specimens, the collection of which was begun in 1988, the year in which the technology for HLA molecular typing became available in Pittsburgh. Thus, due to the lack of DNA specimens before 1988, we analysed 248 autoantibody-positive relatives, which represent basically all the antibody positive relatives of our study, and compared the results with those from almost an identical number of autoantibody-negative relatives $(n=252)$.

The demographics of the 500 subjects included in this study were not statistically different from those of all relatives included in the $\mathrm{CHP}$ registry with regard to age (median 30.5 years vs 30 years respectively), percentage of parents (53\% vs $50 \%$ respectively), percentage of siblings ( $47 \%$ vs $50 \%$ respectively) and race (percentage of Blacks: $4 \%$ vs $5 \%$ respectively). Therefore, the subgroup in this study is probably representative of the whole population of first-degree relatives of the CHP registry. Males and females were nearly equally represented in this subgroup of relatives, with $56 \%$ being female. In addition, the same demographic criteria in seronegative patients were not statistically different from those of seropositive relatives.

Diabetes was diagnosed according to standard National Diabetes Data Group criteria [29]. All the subjects, or their parents, gave their informed consent to be studied, and the protocol was approved by the Human Rights Committee of the CHP.

From the whole subgroup of 500 relatives, serum samples had been obtained in 74 initially normoglycaemic prediabetics before they developed insulin-requiring diabetes (follow-up range: $0.3-16.8$ years; median follow-up: 5.9 years). The first 
serum sample drawn from the remaining 426 first degree relatives who did not develop diabetes during follow-up (followup range: $0.1-17.2$ years; median follow-up: 7.2 years), were also analysed.

The first blood samples drawn were assayed using rat pancreas. Any sample with 5 JDF units or more and all consecutive samples from patients who developed diabetes were assayed for cytoplasmic ICA on human pancreas substrate, followed by GAD65 and IA-2 autoantibody determination. The criteria for $H L A$ typing were the following all prediabetics; all relatives with an ICA titre of $10 \mathrm{JDF}$ units or more on rat pancreas and/or 5 JDF units or more on human pancreas; all ICA negative relatives from whom a DNA sample was obtained from the year 1988 through 1992. Some of these first-degree relatives were part of a multiplex family study $[11,20]$.

Laboratory methods: molecular typing of HLA class II alleles. Molecular HLA typing was carried out using sequence-specific priming and exonuclease-released fluorescence (SSPERF), as previously described [30-32]. Briefly, this methodology involves designing and purifying double-labelled fluorescent probes for the detection of class I and class II alleles in PCR amplified DNA samples without the need of agarose gels for reading results.

GAD65 and IA-2 autoantibody radioimmunoassays. Autoantibodies against GAD65 and IA-2 were detected in triplicate using in vitro transcribed/translated ${ }^{35} \mathrm{~S}$-[Met]-labelled recombinant human glutamic acid decarboxylase (GAD65, $65 \mathrm{kDa}$ isoform) as previously described [33] and the ${ }^{35} \mathrm{~S}$-[Met]-labelled recombinant human IA-2. The GAD65 construct used for this study was kindly donated by Dr. A. Lernmark and the IA-2 construct (ICA512bdc) [33, 34] was kindly provided by Dr. G. Eisenbarth. The results are expressed as an index (index = sample $\mathrm{cpm}-$ negative control $\mathrm{cpm} /$ positive control $\mathrm{cpm}-$ negative control $\mathrm{cpm}$ ) as previously reported [35]. The GAD65 and IA-2 assays have repeatedly performed very well in the GAD and IA-2 autoantibody proficiency workshops. In-house laboratory thresholds for positivity gave excellent performance in multiple workshops. Results of the proficiency workshops organized by the University of Florida in Gainesville (1995, 1996 and 1997), and the Diabetes Autoantibody Standardization Programme (DASP, 2000), organized by WHO, the data were: $76-100 \%$ sensitivity, 90-100\% specificity (100\% specificity 3 times), and $100 \%$ validity for GAD autoantibodies; 48-78.5\% sensitivity, $98-100 \%$ specificity, $87.5 \%$ validity and $91.6 \%$ consistency in the 1996 and 2000 for IA-2 autoantibodies.

Insulin autoantibody (IAA) radioimmunoassay. Insulin autoantibodies were detected in triplicate using a radioimmunoassay. Serum samples $(5 \mu \mathrm{l})$ were incubated with ${ }^{125}$ I-labelled insulin, as previously described [36]. Three quality controls were included in each assay: sera obtained from long-standing insulin-treated patient (high control); IAA positive first-degree relative of Type I diabetic patients (medium control); and serum from a healthy volunteer (negative control). A standard curve was generated for each assay. The cut-off point, established as the 99th percentile of autoantibodies calculated using 272 control subjects, was set at 0.16 units. For IAA the inter-assay $\mathrm{CV}$ was $19.4 \%(n=15)$, whereas the intra-assay CV was $8.0 \%(n=15)$. Insulin autoantibodies gave $16 \%$ sensitivity and $100 \%$ specificity, which was averaged in the most recent DASP workshop.

Cytoplasmic islet cell antibodies (ICA). ICA were detected by histochemical procedures [37]. The cut-off point for analyses in this study was set at $10 \mathrm{JDF}$ units or more, as is applied in the United States for the enrolment of patients in the Diabetes Prevention Trial 1 (DPT-1) [38]. This assay is a modification of immunoperoxidase assay using both rat and human pancreas as substrate [39, 40]. All samples were initially screened using rat pancreas. If the ICA result was 5 JDF units or more, the sample was re-tested using human pancreases. In this report we used rat ICA data due to the easy availability of rat pancreas as substrate to carry out the assay in every sample. However, the data were also analysed using ICA detected on human substrate with only 22 out of 426 non-prediabetic subjects excluded, because insufficient serum was available. The results using the human ICA were virtually identical with those of rat ICA. The ICA assay consistently performed with a $64-100 \%$ sensitivity and $88-99 \%$ specificity, $77-100 \%$ validity in JDFI sponsored proficiency tests from 1991 to 1996.

Statistical analysis. Data were analysed using the Statistical Analysis System Software on Windows operating system (Release 6.12; SAS Institute, Cary, N.C., USA) and SPSS software (SPSS, Chicago, Ill., USA). The chi square $\left(\chi^{2}\right)$ test was used to compare proportions and detect a statistically significant association between two variables. Fisher's exact test was used if any expected cell value in a $2 \cdot 2$ table was less than 5 . A $p$ value of less than 0.05 was considered to be statistically significant. The length of follow-up was calculated from the time of the blood sampling to the last contact with the subject, or the onset of Type I diabetes. Survival analysis was used to estimate the cumulative risk of developing diabetes onset with data censored according to length of follow-up. Survival curves were compared using the log-rank test. Point estimates of risk were quoted as cumulative risk $(95 \%-\mathrm{CI})$.

\section{Results}

Higher prevalence of 2 HLA-DQ high-risk haplotypes in seronegative prediabetics compared to seronegative non-diabetic selectives. Of the 500 HLA genotyped relatives, 252 were autoantibody negative and 248 were autoantibody positive at their first blood draw. Among the 252 autoantibody negative relatives, there were 15 prediabetics, while among the 248 autoantibody positive relatives there were 59 prediabetics. Autoantibody negative prediabetics had a statistically significant higher prevalence of 2 $H L A-D Q$ high-risk haplotypes compared to non-diabetic autoantibody negative first-degree relatives $(33.3 \%$ vs $10.1 \% ; p<0.05)$. In contrast, the prevalence of $2 H L A-D Q$ high-risk haplotypes was not statistically different in prediabetics with 1,2 or more islet autoantibodies, at their initial blood draw, compared to non-diabetic relatives. It should be noted that among prediabetics there was no statistically significant difference in the prevalence of 0,1 or $2 H L A$ $D Q$ high-risk haplotypes in any antibody group.

Prevalence of HLA-DQ high-risk haplotypes and islet cell autoantibody markers and age. The prevalence of $2 H L A-D Q$ high-risk haplotypes and four islet cell autoantibody markers (four autoantibody markers $+2 H L A-D Q$ high-risk haplotypes as the fifth 
Table 1. Two $H L A-D Q$ high-risk haplotypes and islet autoantibodies in three age groups of 500 first-degree relatives of Type I diabetic patients who developed or did not develop insulin-requiring diabetes. These analyses are based on the results obtained by assaying the first serum sample available in these relatives

\begin{tabular}{|c|c|c|c|c|c|c|}
\hline & \multicolumn{3}{|c|}{$\begin{array}{l}\text { Prediabetics }(n=74) \\
\text { Age-group (years) }\end{array}$} & \multicolumn{3}{|c|}{$\begin{array}{l}\text { Non-diabetic relatives }(n=426) \\
\text { Age-group (years) }\end{array}$} \\
\hline & $\begin{array}{l}<17 \\
(n=34)\end{array}$ & $\begin{array}{l}17-40 \\
(n=26)\end{array}$ & $\begin{array}{l}>40 \\
(n=14)\end{array}$ & $\begin{array}{l}<17 \\
(n=130)\end{array}$ & $\begin{array}{l}17-40 \\
(n=204)\end{array}$ & $\begin{array}{l}>40 \\
(n=92)\end{array}$ \\
\hline $2 H L A-D Q$ high-risk haplotypes & $35.3[0.2-0.53]$ & $19.2[0.07-0.39]$ & $42.9^{\mathrm{a}}[0.18-0.71]$ & $18.5[0.12-0.26]$ & $11.3[0.07-0.16]$ & $16.3^{\mathrm{a}}[0.09-0.25]$ \\
\hline GAD65 Ab & $73.6^{\mathrm{g}}[0.56-0.87]$ & $80.8^{\mathrm{g}}[0.61-0.93]$ & $50^{\mathrm{c}}[0.23-0.77]$ & $15.4^{\mathrm{g}}[0.1-0.23]$ & $14.7^{\mathrm{g}}[0.1-0.2]$ & $10.1^{\mathrm{c}}[0.05-0.19]$ \\
\hline IA-2 Ab & $47.1^{\mathrm{b}}[0.3-0.65]$ & $42.3[0.23-0.63]$ & $7.1[0.002-0.34]$ & $6.9^{\mathrm{b}}[0.03-0.13]$ & $4.9[0.02-0.09]$ & $1.1[0.0003-0.06]$ \\
\hline IAA & $55.9^{\mathrm{b}}[0.38-0.73]$ & $19.2[0.07-0.39]$ & $7.1[0.002-0.34]$ & $11.5^{\mathrm{b}}[0.07-0.18]$ & $7.8[0.05-0.12]$ & $4.3[0.01-0.11]$ \\
\hline ICA & $61.8[0.44-0.78]$ & $34.6[0.17-0.56]$ & $35.7[0.13-0.65]$ & $36.9[0.29-0.46]$ & $31.4[0.25-0.38]$ & $32.6[0.23-0.43]$ \\
\hline No Markers & $8.8^{\mathrm{c}}[0.02-0.23]$ & $7.7^{\mathrm{f}}[0.001-0.25]$ & $35.7[0.13-0.65]$ & $43.1^{\mathrm{c}}[0.034-0.52]$ & $50.1^{\mathrm{f}}[0.44-0.58]$ & $55.4[0.45-0.66]$ \\
\hline 1 Marker & $14.7^{\mathrm{b}}[0.05-0.31]$ & $38.5[0.2-0.59]$ & $21.4[0.05-0.51]$ & $38.5^{\mathrm{b}}[0.3-0.47]$ & $36.3[0.3-0.43]$ & $25[0.17-0.35]$ \\
\hline 2 Markers & $14.7[0.05-0.31]$ & $23.1^{\mathrm{a}}[0.09-0.44]$ & $21.4[0.05-0.51]$ & $10.1[0.06-0.17]$ & $6.9^{\mathrm{a}}[0.04-0.11]$ & $17.4[0.1-0.27]$ \\
\hline 3 Markers & $26.5^{\mathrm{e}}[0.11-0.41]$ & $15.4^{\mathrm{a}}[0.04-0.35]$ & $14.3^{\mathrm{a}}[0.02-0.43]$ & $2.3^{\mathrm{e}}[0.005-0.07]$ & $3.9^{\mathrm{a}}[[0.02-0.08]$ & $2.2^{\mathrm{a}}[0.003-0.08]$ \\
\hline 4 Markers & $26.5^{\mathrm{d}}[0.11-0.41]$ & $11.5^{\mathrm{a}}[0.02-0.3]$ & $0[0-0.23]$ & $4.6^{\mathrm{d}}[0.02-0.1]$ & $2^{\mathrm{a}}[0.005-0.05]$ & $0[0-0.04]$ \\
\hline 5 Markers & $8.8^{\mathrm{a}}[0.02-0.24]$ & $3.8[0.001-0.2]$ & $7.1[0.002-0.34]$ & $0.8^{\mathrm{a}}[0.0002-0.04]$ & $0[0-0.02]$ & $0[0-0.04]$ \\
\hline \multicolumn{3}{|c|}{$\begin{array}{l}\text { Data are expressed as age-group-specific percentages within } \\
\text { prediabetics and non-diabetic relatives } \\
{[95 \%-C I \text { for } \pi \text { (proportions)] }} \\
\text { Comparisons among prediabetics vs non-diabetic relatives by } \\
\text { age groups }\end{array}$} & $\begin{array}{l}{ }^{\mathrm{a}} \mathrm{p}<0.05 \\
{ }_{\mathrm{b}} \mathrm{p}<0.01 \\
{ }_{\mathrm{c}}^{\mathrm{p}}<0.001 \\
{ }_{\mathrm{d}} \mathrm{p}<0.0005 \\
{ }_{\mathrm{e}} \mathrm{p}<0.0001 \\
{ }_{\mathrm{f}} \mathrm{p}<0.000005 \\
{ }_{\mathrm{g}} \mathrm{p}<0.000001\end{array}$ & & & \\
\hline
\end{tabular}

marker) was evaluated in prediabetics and non-diabetic relatives of three different age groups (Table 1). Interestingly, as in the younger prediabetics, the presence of $2 H L A-D Q$ high-risk haplotypes was higher in prediabetics aged 40 years or more compared to non-diabetic relatives over 40 years of age $(42.9 \%$ vs $16.3 \%$ respectively; $p<0.05$ ).

The prevalence of autoantibodies to insulin, GAD65, IA-2 and ICA was higher in the prediabetics aged under 17, between 17 and 40 years and over 40 years of age compared to that of non-diabetic relatives (Table 1) and was also higher in those aged under 17 and between 17 and 40 years compared to that of those over 40 years of age (Table 1 ).

Table 2 shows the demographic characteristics and the $H L A-D Q$ genotypes of 15 prediabetics who were seronegative at first serum sampling and developed insulin requirement during follow-up. Of interest, 12 out of $15(80 \%)$ of these individuals were Caucasian. In prediabetics with multiple serum sampling, autoantibody status before, at, and after the onset of insulin-requiring diabetes is shown in Table 3. We demonstrated and confirmed that the majority of relatives have stable antibody patterns over time, and only approximately $20 \%$ of individuals sero-convert during follow-up. Multiple serum samples were available before the onset of insulin-requiring diabetes in 10 out of 15 prediabetics that were seronegative at their first blood draw. In particular, two out of these 10 individuals sero-converted from negative to positive (Table 3). Those two prediabetics developed GAD65 as well as IA-2 autoantibodies, and GAD65 autoantibodies as well as cytoplasmic ICA before diabetes onset, documented 0.8 and 4.5 years before diabetes on- set, respectively. Post-diabetes diagnosis samples were available in seven of these 10 prediabetics, five of whom remained seronegative. Two of the post-diagnosis samples that were not available, were negative for autoantibodies in two and three further prediagnosis, follow-up serum samples (Table 3 ).

Progression to insulin requirement in seronegative relatives carrying 2 HLA-DQ high-risk haplotypes. Because $20.3 \%$ (15 out of 74 ) of prediabetics were negative for any of the four conventional antibodies to insulin, GAD65, IA-2 and cytoplasmic ICA, we assessed whether $H L A-D Q$ high-risk haplotypes are major risk factors for insulin requirement in seronegative relatives using survival analysis (Fig. 1; Table 4). This analysis is based on the results obtained from the first serum sample in these relatives. In these 252 seronegative relatives, $2 H L A-D Q$ high-risk haplotypes conferred a cumulative risk to develop clinical Type I diabetes of $27 \%$ after a follow-up of 12.5 years, compared to a risk of $6 \%$ for relatives who had 0 or 1 $H L A-D Q$ high-risk haplotypes (Log rank $p=0.01$ ) (Fig. 1; Table 4). Of note, it was the availability of a long follow-up of 12.5 years of seronegative individuals that enabled us to identify a seronegative phenotype carrying $2 H L A-D Q$ high-risk haplotypes that develops insulin requirement. At 5 years' follow-up none of these seronegative relatives carrying 2 $H L A-D Q$ high-risk haplotypes had developed the clinical features of diabetes (Fig. 1; Table 4). Figure 2 depicts as an example, one seronegative prediabetic subject (Patient No. 1 in Tables 2 and 3) who had 2 $H L A-D Q$ high-risk haplotypes and developed insulin-requiring diabetes. 
Table 2. Clinical characteristics and $H L A-D Q$ genotypes of seronegative prediabetics

\begin{tabular}{|c|c|c|c|c|c|c|c|c|c|}
\hline $\begin{array}{l}\text { Patient } \\
\text { number }\end{array}$ & Race & $\begin{array}{l}\text { Age at first } \\
\mathrm{Ab} \text { sample } \\
\text { assayed (year) }\end{array}$ & $\begin{array}{l}\text { Time interval } \\
\text { of last Ab } \\
\text { sample and } \\
\text { diagnosis (year) }\end{array}$ & $\begin{array}{l}\text { Age at } \\
\text { diagnosis } \\
\text { (year) }\end{array}$ & $D Q A 1 \alpha$ & $D Q A 1 \beta$ & $D Q B 1 \alpha$ & $D Q B 1 \beta$ & $\begin{array}{l}H L A-D Q \\
\text { high-risk } \\
\text { haplotypes } \\
(n)\end{array}$ \\
\hline 2 & $\mathrm{C}$ & 6.1 & 0.8 & 11.5 & 0501 & 0501 & 0201 & 0301 & 1 \\
\hline 3 & $\mathrm{C}$ & 8.7 & 0.6 & 12.8 & 01 & 0201 & 0201 & 0501 & 0 \\
\hline 4 & $\mathrm{C}$ & 9.0 & $7.8^{\mathrm{a}}$ & 16.7 & 0301 & 0301 & 0302 & 0602 & 1 \\
\hline 7 & A & 20 & 5.8 & 34.7 & 01 & 0301 & 0302 & 0502 & 1 \\
\hline 8 & $\mathrm{C}$ & 30.8 & 0.8 & 37.8 & 0102 & 0301 & 0602 & 0201 & 0 \\
\hline 9 & $\mathrm{C}$ & 36.7 & $6.2^{\mathrm{a}}$ & 43 & 0301 & 0301 & 0302 & 0302 & 2 \\
\hline 10 & $\mathrm{C}$ & 43 & $11.5^{\mathrm{a}}$ & 54.5 & 0501 & 0501 & 0201 & 0201 & 2 \\
\hline 11 & A & 43.6 & 4.8 & 54 & 0102 & 0501 & 0301 & 0602 & 0 \\
\hline 12 & $\mathrm{C}$ & 44.7 & 8.9 & 55.1 & 0501 & 0501 & 0201 & 0301 & 1 \\
\hline
\end{tabular}

A, African American; C, Caucasian

a Only one serum sample was available prior to insulin-requiring diabetes onset

Table 3. Multiple serum samples available from 10 out of $15 H L A-D Q$ typed seronegative prediabetic patients prior to insulin-requiring diabetes onset (first draw date) that were sequentially assayed for GAD65 Ab, IA-2 Ab, IAA and cytoplasmic ICA

\begin{tabular}{|c|c|c|c|c|c|}
\hline Patient No. & $\begin{array}{l}H L A-D Q \text { high-risk } \\
\text { haplotypes }(n)\end{array}$ & $\begin{array}{l}\text { Multiple samples tested } \\
\text { prior to diabetes onset }(n)\end{array}$ & $\begin{array}{l}\text { Antibody status prior } \\
\text { to diabetes onset }\end{array}$ & $\begin{array}{l}\text { Samples tested at } \\
\text { or after DM onset }^{\text {a }}\end{array}$ & $\begin{array}{l}\text { Antibody status at } \\
\text { or after DM onset }^{\mathrm{a}}\end{array}$ \\
\hline 1 & 2 & 5 & Negative & 1 & Negative \\
\hline 2 & 1 & 3 & Negative to Positive ${ }^{b}$ & 2 & Positive $^{\mathrm{b}}$ \\
\hline 6 & 2 & 4 & Negative & 1 & Positive $^{c}$ \\
\hline 7 & 1 & 2 & Nega tive & 0 & - \\
\hline 8 & 0 & 6 & Negative & 1 & Negative \\
\hline 14 & 0 & 3 & Negative & 1 & Negative \\
\hline 15 & 1 & 3 & Negative to Positive ${ }^{b}$ & 0 & - \\
\hline
\end{tabular}

Patients No 1 and 6 carry $2 H L A-D Q$ high-risk haplotypes and remain autoantibody negative over time prior to the onset of insulin-requiring diabetes

${ }^{a}$ After diabetes onset, IAA were not assayed because of the real possibility of positive results following insulin treatment ${ }^{b}$ Patients No. 2 developed positivity for GAD65, IA-2 autoantibodies, IAA and cytoplasmic ICA and patient No. 15 devel-

On selecting the subgroup of relatives who had two or more autoantibodies, a condition that is associated with a high cumulative risk of developing insulin requirement [2], we found that the presence of 2 $H L A-D Q$ high-risk haplotypes did not confer any further risk of developing diabetes over time (Fig. 3; Table 5).

Progression rate of insulin-requiring diabetes using islet autoantibody and HLA-DQ high-risk haplotype assessment. When the four islet autoantibody markers were combined with $2 H L A-D Q$ high-risk haplotypes as a fifth marker, there was a cumulative risk of approximately $50 \%$ for developing diabetes within 5 years and $83 \%$ at 8 years, remaining at $83 \%$ after a oped GAD65 autoantibodies and cytoplasmic ICA prior to diabetes onset. In these two patients, sero-conversion was documented 0.8 and 4.5 years prior to diabetes onset respectively 'Patient No. 6 developed cytoplasmic ICA (10 JDF Units ) at the onset of insulin-requiring diabetes, while was negative for GAD65 and IA-2 autoantibodies

( - ) No serum was available

longer follow-up (Fig. 4; Table 6). When the four autoantibody markers alone were evaluated, the presence of four autoantibodies to islet autoantigens alone, conferred a cumulative risk of $49 \%$ at 5 years, and $81 \%$ at 8,10 and 12.5 years (Fig. 5; Table 7 ).

In sum, the addition of $H L A-D Q$ molecular typing as another marker does not appear to increase the rate of progression at 5 years compared to the presence of four autoantibodies. The presence of a fourth marker, whether $2 H L A-D Q$ high-risk haplotypes or autoantibody markers, gives the best cumulative risk of the development of Type I diabetes at 5 years $(\sim 50 \%)$ and at 8 years $(\sim 80 \%)$ (Fig. 4 ; Table 6$)$. The presence of at least three autoantibody markers appears to be a better predictor of insulin require- 


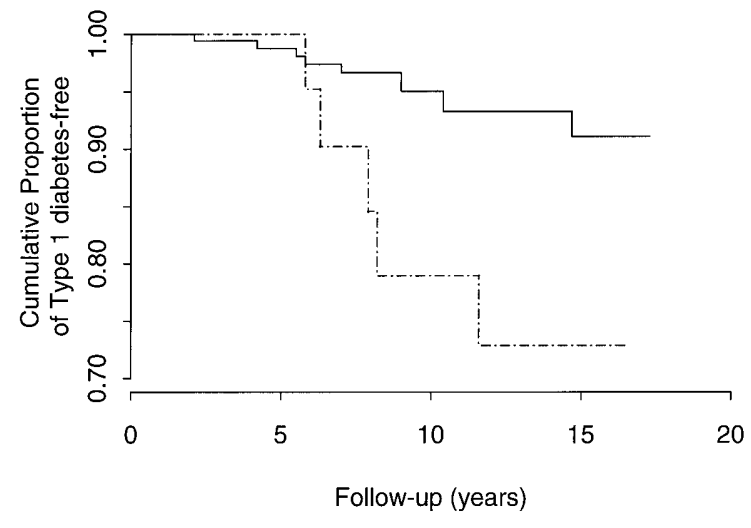

Number of HLA-DQ High Risk Haplotyes

$\begin{array}{ccccc}\text { 0 or } 1: 221 & 149 & 110 & 36 \\ 2: 31 & 21 & 14 & 6\end{array}$

Fig. 1. Progression to insulin-requiring diabetes for seronegative relatives $(n=252)$ who carry two compared with zero or one $H L A-D Q$ high-risk haplotypes. Two $H L A-D Q$ high-risk haplotypes conferred a cumulative risk to insulin-requiring diabetes of $27 \%$ after a follow-up of 12.5 years, compared to a risk of $6 \%$ for relatives who had zero or one $H L A-D Q$ highrisk haplotypes (log rank $p=0.01)$. (-) 0 or $1 H L A-D Q$ high-risk haplotypes; $(\cdot-\cdot-) 2 H L A-.D Q$ high-risk haplotypes

ment (Fig. 5; Table 7) than two autoantibody markers alone ( $\log$ rank, $p=0.01$ ). However, the presence of two or more autoantibody markers conferred a cumulative risk of only $30 \%$ at 5 years and of $57 \%$ at 10 years, whereas the presence of four autoantibody markers, which is considered a strong risk factor for diabetes progression, conferred a cumulative risk of $49 \%$ and $81 \%$ at 5 and 10 years, respectively.

Seronegative prediabetics and HLA-DQB*0602. Altogether $7 \%$ (5 out of 74 ) of prediabetics carried the HLA haplotype $D Q A 1 * 0102-D Q B 1 * 0602$ or $D Q A 1 * 0301-D Q B 1 * 0602$ (Table 2). Moreover, $26.7 \%$ (4 out of 15 ) of seronegative prediabetics carried the HLA haplotype $D Q A 1 * 0102-D Q B 1 * 0602$ compared to $1.7 \%$ (1 out of 58 ) of autoantibody positive (positive for at least $1 \mathrm{Ab}$ ) prediabetics $(p=0.005)$. Only three out of 15 prediabetics with no signs of humoral islet cell autoimmunity were African-American and two out of three of these individuals carried the $H L A$ haplotype $D Q B 1 * 0602$ (Table 2).

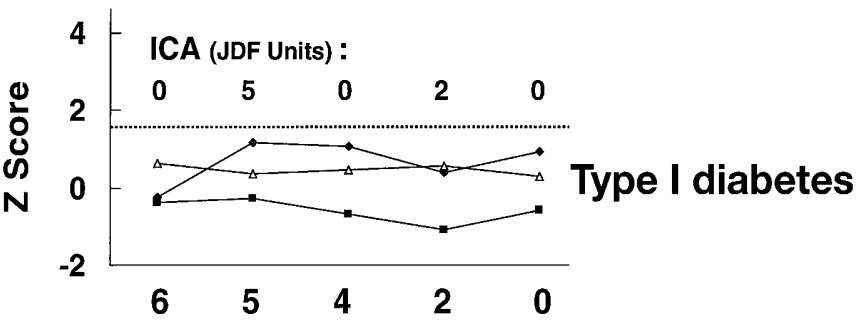

Years prior to Type I diabetes

Fig. 2. Sequential evaluation of islet autoantibodies in a 9year-old relative carrying $2 H L A-D Q$ high-risk haplotypes who progressed to clinical diabetes. The $\mathrm{Z}$ score (or standard score), for GAD65 and IA-2 and insulin autoantibody values, was calculated by finding the difference between the value of a particular observation (index of a particular time point), the mean of the distribution (mean of index from 280 controls for GAD65 and IA-2 and 272 controls for IAA), and dividing this difference by the standard deviation. The thresholds for GAD65 and IA-2 and insulin autoantibody assays (- - -). The values of ICA are expressed in JDF units for each time point. $(\neg)$, GAD65 Ab; $(-\bullet)$, IA-2Ab; $(-\bullet)$, IAA)

\section{Discussion}

The American Diabetes Association in 1997 revised the criteria for the diagnosis and classification of diabetes mellitus based on the presence of signs of humoral islet cell autoimmunity [5]. Although autoimmune diabetes usually presents in childhood or adolescence [41], it can also occur from early to late adulthood [42-44]. Islet cell autoantibody testing can now be standardized worldwide [45] and is currently used as a major criterion for enrolment in current intervention trials $[38,46]$.

We identified a diabetes phenotype that is characterized by the absence of conventional autoantibody markers of islet cell autoimmunity (cytoplasmic ICA, insulin, GAD65 and IA-2 autoantibodies), the presence of $2 H L A-D Q$ high-risk haplotypes and the development of insulin requirement during followup. It should be noted that sero-conversion during follow-up is a rather unusual event. Our data, shown in Table 3, strengthen what we and others have previously reported [47, 48], indicating (Bingley PJ et al; Pietropaolo $\mathrm{M}$ et al.; unpublished observations), that the majority of relatives have stable positive or negative antibody patterns over time, and that only about

Table 4. Cumulative risk of developing insulin-requiring diabetes for different years of follow-up among seronegative relatives $(n=252)$ by number of $H L A-D Q$ high-risk haplotypes ( 2 vs 0 or 1$)$. [95\%-CI].

\begin{tabular}{|c|c|c|c|c|c|}
\hline $\begin{array}{l}\text { Number of } H L A-D Q \\
\text { High-risk Haplotypes }\end{array}$ & $\begin{array}{l}\text { Type I dia- } \\
\text { betes cases }\end{array}$ & $\begin{array}{l}\text { Cumulative risk of } \\
\text { diabetes within } 5 \text { years }\end{array}$ & $\begin{array}{l}\text { Cumulative risk of } \\
\text { diabetes within } 8 \text { years }\end{array}$ & $\begin{array}{l}\text { Cumulative risk of } \\
\text { diabetes within } 10 \text { years }\end{array}$ & $\begin{array}{l}\text { Cumulative risk of } \\
\text { diabetes within } 12.5 \text { years }\end{array}$ \\
\hline 0 or 1 & 10 & {$[0-5]$} & [1-8] & [2-10] & [4-13] \\
\hline 31 & 5 & 0 & [5-41] & [8-47] & {$[12-54]$} \\
\hline
\end{tabular}

Survival function of $H L A-D Q$ high-risk haplotype groups (0 or 1 vs 2$)$ among seronegative relatives (log-rank statistics = 6.2; $\mathrm{df}=1, p=0.0128)$. df, degree of freedom 


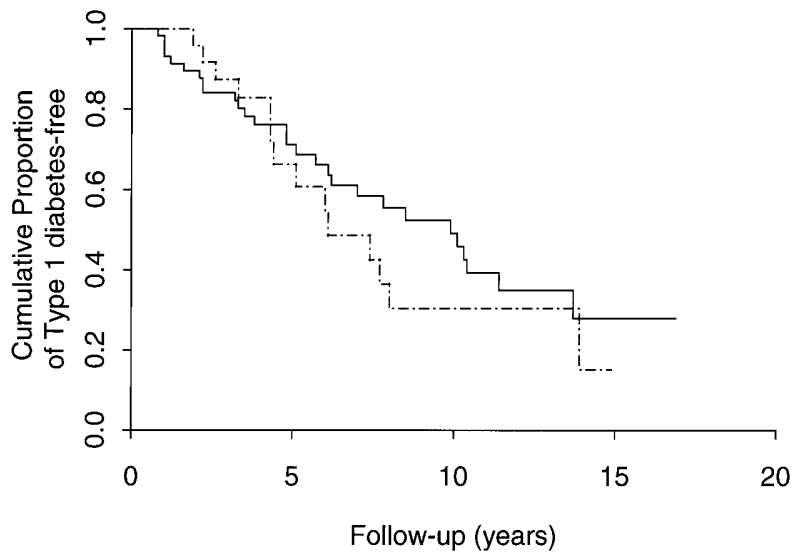

Numbers of HLA-DQ Haplotyes

$$
\begin{array}{cccc}
0 \text { or } 1: 59 & 28 & 15 & 4 \\
2 & 12 & 5 &
\end{array}
$$

Fig.3. Progression to insulin-requiring diabetes for relatives with at least two autoantibody markers $(n=85)$ (IAA, GAD65, IA-2 Abs, and ICA) in relation to the number of $H L A-D Q$ high-risk haplotypes (two vs zero or one). In these relatives, who are at significant risk of developing diabetes, the presence of $2 H L A-D Q$ high-risk haplotypes did not confer any further risk. (-) 0 or $1 H L A-D Q$ high-risk haplotypes; (.-.-.) 2 HLA-DQ high-risk haplotypes

$20 \%$ of individuals sero-convert during follow-up. Sero-conversion to autoantibody positivity cannot be excluded in those three seronegative prediabetics (Table 3) carrying $2 H L A-D Q$ high-risk haplotypes in the time interval from the last sample collected before the diagnosis of insulin-requiring diabetes. Additional serum from those individuals is not available.

The addition of $H L A-D Q$ genotypes does not increase the sensitivity of combined autoantibody as-

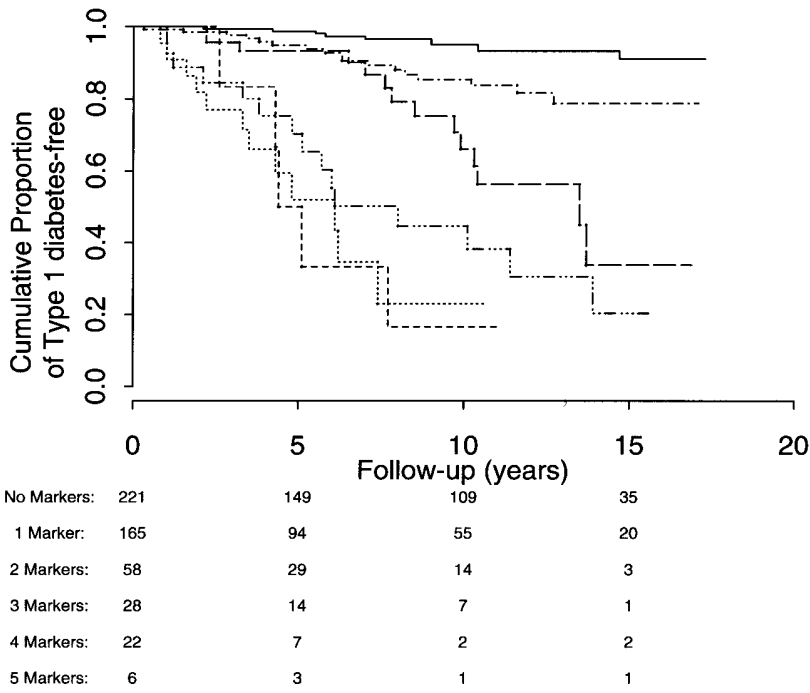

Fig. 4. Progression to insulin-requiring diabetes among the whole subgroup of relatives $(n=500)$ in relation to the number of markers (four autoantibody markers + $2 H L A-D Q$ highrisk haplotypes). (- $)$ No Markers; (.-.-.) 1 Marker; (- -) 2 Markers; (....-) 3 Markers; (....) 4 Markers; (-...-) 5 Markers

says, but rather suggests that unidentified autoimmune phenomena could be present in seronegative relatives carrying $2 H L A-D Q$ high-risk haplotypes who will eventually develop insulin-requiring diabetes. It is also possible that autoantibody-negative first degree relatives who progress to diabetes could have T cell but no detectable autoantibody responses [49].

A significant number of autoantibody negative children and adults affected by insulin-requiring diabetes have disorders associated with non-autoim-

Table 5. Cumulative risk of developing insulin-requiring diabetes for different years of follow-up among relatives selected for having at least two autoantibody markers $(n=85)$, by number of $H L A-D Q$ high-risk haplotypes $(2$ vs 0 or 1$)$ [95\%-CI].

\begin{tabular}{|c|c|c|c|c|c|}
\hline $\begin{array}{l}\text { Number of } H L A-D Q \\
\text { High-risk Haplotypes }\end{array}$ & $\begin{array}{l}\text { Type I dia- } \\
\text { betes cases }\end{array}$ & $\begin{array}{l}\text { Cumulative risk of } \\
\text { diabetes within } 5 \text { years }\end{array}$ & $\begin{array}{l}\text { Cumulative risk of } \\
\text { diabetes within } 8 \text { years }\end{array}$ & $\begin{array}{l}\text { Cumulative risk of } \\
\text { diabetes within } 10 \text { years }\end{array}$ & $\begin{array}{l}\text { Cumulative risk of } \\
\text { diabetes within } 12.5 \text { years }\end{array}$ \\
\hline 59 & 28 & {$\left[\begin{array}{ll}18 & 43\end{array}\right]$} & $\lceil 31,601$ & [37-67] & 64 \\
\hline 26 & 14 & [17-58] & [42-84] & [48-88] & [48-88] \\
\hline
\end{tabular}

Survival function of $H L A-D Q$ high-risk haplotype groups (0 or 1 vs 2 ) among these seropositive relatives (log-rank statistics = 0.4 ; df $=1, p=0.503)$. df, degree of freedom

Table 6. Cumulative risk of developing insulin-requiring diabetes for different years of follow-up among the whole subgroup of relatives $(n=500)$ by number of markers (four autoantibody markers $+2 H L A$ - $D Q$ high-risk haplotypes). [95\%-CI].

\begin{tabular}{|c|c|c|c|c|c|c|c|c|c|c|}
\hline \multicolumn{2}{|c|}{ Number of markers } & \multirow{2}{*}{$\begin{array}{l}\text { Type I } \\
\text { diabetes } \\
\text { cases }\end{array}$} & \multicolumn{2}{|c|}{$\begin{array}{l}\text { Cumulative risk } \\
\text { of diabetes within } \\
5 \text { years }\end{array}$} & \multicolumn{2}{|c|}{$\begin{array}{l}\text { Cumulative risk } \\
\text { of diabetes within } \\
8 \text { years }\end{array}$} & \multicolumn{2}{|c|}{$\begin{array}{l}\text { Cumulative risk } \\
\text { of diabetes within } \\
10 \text { years }\end{array}$} & \multicolumn{2}{|c|}{$\begin{array}{l}\text { Cumulative risk } \\
\text { of diabetes within } \\
12.5 \text { years }\end{array}$} \\
\hline No Markers & 221 & & 1 & {$[0-5]$} & 3 & {$[1-8]$} & 4 & {$[2-10]$} & 7 & {$[4-13]$} \\
\hline 2 Markers & 58 & 14 & 7 & [2-19] & 21 & [10-40] & 34 & [19-55] & 44 & {$[27-66]$} \\
\hline 3 Markers & 28 & 15 & 30 & [15-53] & 50 & [31-72] & 55 & [36-77] & 69 & {$[48-89]$} \\
\hline 4 Markers & 22 & 12 & 48 & [28-73] & 77 & [50-95] & 77 & [50-95] & 77 & {$[50-95]$} \\
\hline
\end{tabular}

Survival function of five marker groups (log-rank statistics $=162 ; \mathrm{df}=5, p=0)$. df degree of freedom 


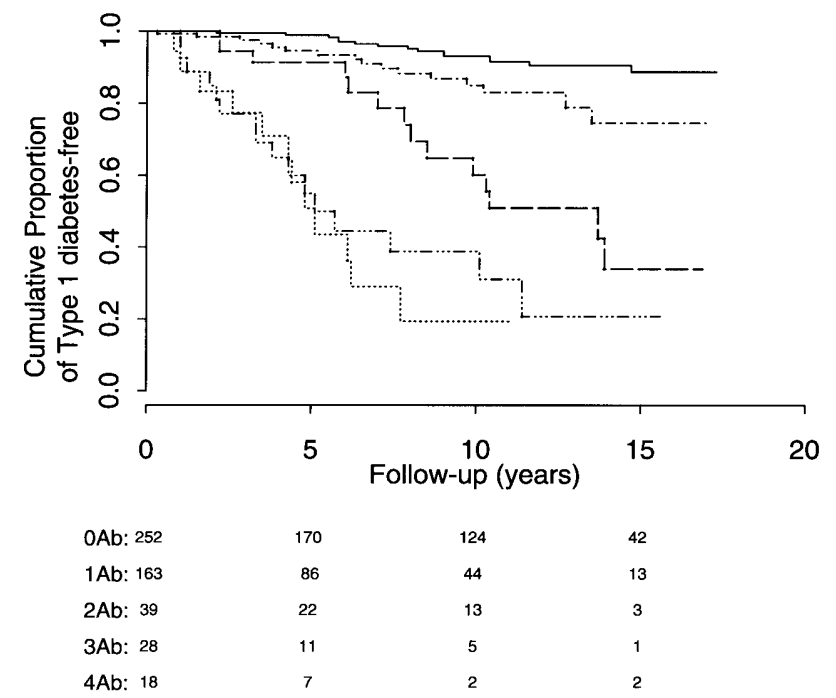

Fig. 5. Progression to insulin-requiring diabetes among the whole subgroup of relatives $(n=500)$ in relation to the number of autoantibodies (Ab) to insulin GAD65, IA-2 and ICA. Relatives who are positive for 3 or $4 \mathrm{Ab}$ are at much greater risk of developing diabetes compared to relatives with $2 \mathrm{Ab}$ alone. (log rank: $p=0.0096$ and 0.001 respectively). (-) No $\mathrm{Ab}$; $(\cdot-\cdot-\cdot) 1 \mathrm{Ab} ;(--) 2 \mathrm{Ab} ;(\cdot-\cdots-) 3 \mathrm{Ab} ;(\cdots \cdots) 4 \mathrm{Ab}$

mune diabetes [3]. The question is whether these seronegative relatives carrying $2 H L A-D Q$ high-risk haplotypes and developing insulin-requiring diabetes have a unique form of non-autoimmune Type I diabetes. The answer is probably not because the genetic susceptibility to autoimmune diabetes is strongly conferred by $H L A-D Q \quad D Q A 1 * 0501$ $D Q B 1 * 0201$, and $D Q A 1 * 0301-D Q B 1 * 0302$ haplotypes. This concept is substantiated by recently published in vivo experimental evidence for the contribution of $H L A-D Q$ molecules to autoimmune-related diabetes development using a unique "humanized" animal model of diabetes [17]. The possibility that $2 H L A-D Q$ high-risk haplotypes are associated with a diabetes subtype of possible non-autoimmune origin, similar to that reported in Japanese populations [50], can also be excluded because of the absence of the HLA-DQ DQA1*0501$D Q B 1 * 0201$, and $D Q A 1 * 0301-D Q B 1 * 0302$ haplotypes in the Japanese populations [50, 51]. An atyp- ical diabetes mellitus (ADM) or Type 1.5 diabetes in African American children has been described [52]. This disease appears to be similar to a form of diabetes seen in adults with signs of diabetic ketoacidosis and absence of GAD antibodies [53]. Heterozygous mutations in the transcription factor $H N F-1 \alpha$ have been found to be associated with ADM in African Americans and Black Africans [3]. In a previous report, we found that African American children have a tendency to a lower prevalence of anti-islet autoantibodies in comparison to Caucasian children [4]. However, it is not likely that seronegative prediabetics carrying $2 H L A-D Q$ high-risk haplotypes have a form of ADM or MODY because the latter disorders are not associated with the presence of susceptible $H L A-D Q / D R$ alleles, and only three out of 15 of our seronegative prediabetics are Afro-American.

A major strength of our study is the long prospective follow-up of first-degree relatives from a specific registry with follow-up of all subjects many of whom have been followed for 20 years irrespective of their autoantibody status. It was the availability of a long follow-up of 12.5 years that enabled us to identify a seronegative phenotype carrying $2 H L A-D Q$ highrisk haplotypes, which develops insulin requirement over time. In these relatives, the presence of 2 $H L A-D Q$ high-risk haplotypes conferred an increased cumulative risk of developing insulin requirement of $27 \%$ only at 12.5 years of follow-up, compared to a risk of $6 \%$ for non-diabetic relatives who were antibody-negative and had 0 or $1 H L A$ $D Q$ high-risk. In contrast, at 5 years follow-up, none of these seronegative relatives carrying $2 H L A-D Q$ high-risk haplotypes developed the clinical features of diabetes. These results strongly suggest that, although autoantibody markers to islet cell antigens are very important tools to estimate diabetes risk [1, $2,55]$, they still appear to be insufficient for accurate prediction of Type I diabetes within 5 or even 10 years $[6,56]$.

In addition, when the four autoantibody markers to GAD65, insulin, IA-2 and cytoplasmic ICA were evaluated, the presence of $4 \mathrm{Abs}$ to these islet antigens conferred a cumulative risk of $49 \%$ at 5 years, $81 \%$ at 8 and 10 years, and $83 \%$ at 12.5 years, as

Table 7. Cumulative risk of developing insulin-requiring diabetes for different years of follow-up among the whole subgroup of relatives $(n=500)$ by number of autoantibody markers $(\mathrm{Ab})$ to the islet antigens insulin GAD65, IA-2 and ICA [95\% CI].

\begin{tabular}{|c|c|c|c|c|c|c|c|c|c|c|}
\hline \multicolumn{2}{|c|}{$\begin{array}{l}\text { Number of Auto- } \\
\text { antibodies }\end{array}$} & \multirow{2}{*}{$\begin{array}{l}\text { Type I dia- } \\
\text { betes cases } \\
15\end{array}$} & \multicolumn{2}{|c|}{$\begin{array}{l}\text { Cumulative risk of } \\
\text { diabetes within } 5 \text { years }\end{array}$} & \multicolumn{2}{|c|}{$\begin{array}{l}\text { Cumulative risk of } \\
\text { diabetes within } 8 \text { years }\end{array}$} & \multicolumn{2}{|c|}{$\begin{array}{l}\text { Cumulative risk of } \\
\text { diabetes within } 10 \text { years }\end{array}$} & \multicolumn{2}{|c|}{$\begin{array}{l}\text { Cumulative risk of } \\
\text { diabetes within } 12.5 \text { years }\end{array}$} \\
\hline $0 \mathrm{Ab}$ & 252 & & 1 & [0-4] & 5 & [2-9] & 7 & [4-12] & 9 & [6-16] \\
\hline $1 \mathrm{Ab}$ & 163 & 17 & 5 & [2-12] & 12 & [6-20] & 15 & [9-25] & 15 & [10-28] \\
\hline $3 \mathrm{Ab}$ & 28 & 16 & 45 & [28-67] & 61 & [41-81] & 61 & [41-81] & 79 & [55-95] \\
\hline $4 \mathrm{Ab}$ & 18 & 12 & 49 & [28-75] & 81 & [56-96] & 81 & [56-96] & 81 & [56-96] \\
\hline
\end{tabular}

Survival function of four Ab groups (log-rank statistics $=168 ; d f=4, p=0)$. $d f$ degree of freedom 
compared to 0 or 1 Abs. Therefore, our results strongly suggest that it is critical that any intervention trial carried out before the clinical onset of Type 1 diabetes must be not only appropriately designed but also take into account the length of follow-up. A duration of at least 10 years seems to be necessary to assess whether prevention therapies are truly beneficial.

We acknowledge that in this study the number of antibody positive compared to antibody negative first-degree relatives is over-represented similar to the vast majority of prospective studies that have thus far been carried out worldwide in relatives. However, if we were to analyse a much larger number of autoantibody negatives, the study would not be more informative than it is now, assuming that the proportions of individuals who carry $H L A-D Q$ high-risk haplotypes would not considerably change, as can be inferred from the literature [24]. Hence, if a larger number of antibody negative relatives were analysed, the study would be over powered and the conclusions drawn after analysing the results would be exactly the same as those reported here. For example, just by comparing our 248 autoantibody positive to 252 autoantibody negative individuals, we have more than enough power to detect the differences reported in the present study, such as those illustrated in Fig. 1.

We expect the presence of new biochemically detectable autoantibody markers, and likely T-cell proliferation assays $[8,9,57,58]$ will surely be identified in individuals carrying $2 H L A-D Q$ high-risk haplotypes who are negative for conventional antibody markers. This will increase our capacity to identify subjects who will develop insulin-requiring diabetes. Our findings reinforce a previous report [59] indicating a higher relative risk for Type I diabetes among individuals having $4 H L A-D Q$ diabetogenic heterodimers as compared to 1 or 2 heterodimers in both ICA positive and ICA negative relatives.

It has been suggested that individuals with $H L A$ $D Q / D R$ high-risk haplotypes will develop Type I diabetes at young ages [60]. However, we found that 2 $H L A-D Q$ high-risk haplotypes can also be present in prediabetics who are over 40 years of age. Although based upon small numbers, our results also suggest that prediabetics carrying the HLA haplotype $D Q A 1 * 0102, D Q B 1^{*} 0602$ have the tendency to be antibody negative for all islet autoantigens. Interestingly, we found that $40 \%$ of prediabetics carrying the HLA haplotype $D Q A 1 * 0102, D Q B 1 * 0602$ were African-American.

In sum, our results suggest that $H L A-D Q$ typing can identify a seronegative phenotype associated with $2 H L A-D Q$ high-risk haplotypes and insulin-requiring diabetes progression, even though sero-conversion to antibody positivity can infrequently be seen in some relatives. In support of our findings, preliminary results indicate that the distribution of $H L A$ genotypes in patients with Type I diabetes diagnosed as having Type IB diabetes, seems to resemble that of Type IA diabetic patients more than that of the background population [7]. These observations all indicate that the classification of autoimmune diabetes based on currently available autoantibody assessment alone should include additional criteria.

In conclusion, in view of the well-known influence of alleles at the HLA locus in the generation of autoimmunity and the preservation of the $M H C$ class II effect in human and murine autoimmune diabetes $(15,17)$, our findings imply that as yet unidentified immunologic abnormalities, such as peripheral blood lymphocyte responses to islet autoantigens $[8,9,61$, 61-63] and humoral responses or both [6], could well be present in seronegative relatives (by conventional antibody markers) carrying $2 H L A-D Q$ high-risk haplotypes and progressing to insulin-requiring diabetes during a prolonged follow-up.

Acknowledgements. This work was supported by NIH grants R01 DK53456 and R01 DK56200 (M. Pietropaolo), by NIH R01 DK46864 (D. J. Becker), by NIH R01 DK24021 (M. Trucco), by an American Diabetes Association Career Development Award (M. Pietropaolo), by the General Clinical Research Center of the Children's Hospital of Pittsburgh, MO1 RR 00084, and by the Renziehausen fund. We gratefully acknowledge the technical assistance of Ms. S. Pietropaolo, A. Darnley, S. Bertera, A. Alexander and J. Gay. We thank Ms. K. Riley, P. Swanson and M. Smith for data collection and management. We also thank D. Stenger for critical reading of this manuscript. Preliminary data pertaining to this work were presented at the 59th meeting of the American Diabetes Association, San Diego, California, USA, June 1999.

\section{References}

1. Bingley PJ, Christie MR, Bonifacio E et al. (1994) Combined analysis of autoantibodies improves prediction of IDDM in islet cell antibody-positive relatives. Diabetes 43: $1304-1310$

2. Verge CF, Gianani R, Kawasaki E et al. (1996) Prediction of type I diabetes mellitus in first degree relatives using a combination of insulin, glutamic acid decarboxylase and ICA512bdc/IA-2 autoantibodies. Diabetes 45: 926-933

3. Boutin P, Gresh L, Cisse A et al. (1999) Missense mutation Gly574Ser in the transcription factor HNF-1 alpha is a marker of atypical diabetes in African-American children. Diabetologia 42: 380-381

4. Libman IM, Pietropaolo M, Trucco M, Dorman JS, LaPorte RE, Becker DJ (1998) B-cell autoimmunity in white and black children and adolescent with insulin-dependent diabetes mellitus. Diabetes Care 22: 1824-1827

5. The Expert Committee on the Diagnosis and Classification of Diabetes Mellitus (1997) Report of the Expert Committee on the Diagnosis and Classification of Diabetes Mellitus. Diabetes Care 20: 1183-1197

6. Pietropaolo M, Becker DJ, Dorman JS et al. (1999) Are GAD65 and IA-2 autoantibodies sufficient to predict Type 1 diabetes? Diabetes 48 [Suppl 1]: A45 (Abstract)

7. Cornell CN, Stankiewicz W, Asher D et al. (2000) Absence of islet autoantibodies at diabetes onset does not rule out Type 1A diabetes. Diabetes 49 [Suppl 1]: A68 (Abstract) 
8. Dosch HM, Cheung RK, Karges W, Pietropaolo M, Becker DJ (1999) Persistent T cell anergy in human type 1 diabetes. J Immunol 163: 6933-6940

9. Brooks-Worrell BM, Juneja R, Minokadeh A, Greenbaum CJ, Palmer JP (1999) Cellular immune responses to human islet proteins in antibody-positive type 2 diabetic patients. Diabetes 48: 983-988

10. Trucco M (1992) To be or not to be ASP 57, that is the question. Diabetes Care 15: 705-715

11. Dorman JS, LaPorte RE, Stone RA, Trucco M (1990) Worldwide differences in the incidence of type 1 diabetes are associated with amino acid variation at position 57 of the HLA-DQ $\beta$ chain. Proc Natl Acad Sci USA 87: 7370-7374

12. Khalil I, D'Auriol L, Gobet M et al. (1990) A combination of HLA-DQ beta Asp 57-negative and HLA-DQ Arg 52 confers susceptibility to insulin-dependent diabetes mellitus. J Clin Invest 85: 1315-1319

13. Gutierrez-Lopez MD, Bertera S, Chantres MT et al. (1992) Susceptibility to Type I diabetes in Spanish patients correlates quantitatively with expression of HLA-DQ $\alpha$ Arg 52 and HLA-DQ $\beta$ non-Asp 57 alleles. Diabetologia 35: 583-588

14. Noble JA, Valdes AM, Cook M, Klitz W, Thomson G, Erlich HA (1996) The role of HLA class II genes in insulindependent diabetes mellitus: molecular analysis of 180 Caucasian, multiplex families. Am J Hum Genet 59: 1134-1148

15. Nepom GT, Kwok WT (1998) Molecular basis for HLADQ association in IDDM. Diabetes 47: 1177-1184

16. Concannon P, Gogolin-Ewens KJ, Hinds DA et al. (1998) A second-generation screen of the human genome for susceptibility to insulin-dependent diabetes mellitus. Nature Genet 19: 292-296

17. Wen L, Wong FS, Tang J et al. (2000) In vivo evidence for the contribution of human histocompatibility leukocyte antigen (HLA)-DQ molecules to the development of diabetes. J Exp Med 191: 97-104

18. Nerup JJ, Platz P, Anderson O et al. (1974) HLA antigens and diabetes mellitus. Lancet ii: 864

19. Todd JA, Bell JI, McDevitt HO (1987) HLA-DQ $\beta$ gene contributes to susceptibility and resistance to insulin-dependent diabetes mellitus. Nature 329: 599-604

20. Morel PA, Dorman JS, Todd JA, McDevitt HO, Trucco M (1988) Aspartic acid at position 57 of the HLA-DQ beta chain protects against Type I diabetes: a family study. Proc Natl Acad Sci USA 85: 8111-8115

21. Nepom JT (1988) Immunogenetics of HLA-associated diseases. Concepts Immunopathol 37: 1113-1119

22. Friday RP, Trucco M, Pietropaolo M (1999) Genetics of Type 1 diabetes mellitus. Diabetes Nutr Metab 12: 3-26

23. Kockum I, Sanjeevi CB, Eastman S et al. (1999) Complex interaction between HLA DR and DQ in conferring risk for childhood type 1 diabetes. Eur J Immunogenet 26: 361-372

24. Dorman JS, Bunker CH (2000) HLA-DQ locus of the human leukocyte antigen complex and Type 1 diabetes mellitus: A HuGE review. Epidemiol Rev 22: 1-10

25. Vanderwalle CL, Coeckelberghs MI, De Leeuw I et al. (1997) Epidemiology, clinical aspects, and biology of IDDM patients under age of 40 years. Comparison of data from Antwerp with complete ascertainment with data from Belgium with $40 \%$ ascertainment. The Belgian Diabetes Registry. Diabetes Care 20: 1556-1561

26. Tiberti C, Buzzetti R, Anastasi E et al. (2000) Autoantibody negative new onset type 1 diabetic patients lacking high risk HLA alleles in a Caucasian population: are these type $1 \mathrm{~b}$ diabetes cases? Diabetes Metab Rev 16: 8-14
27. Sabbah E, Savola K, Ebeling T et al. (2000) Genetic, autoimmune, and clinical characteristics of childhoodand adult-onset Type 1 diabetes. Diabetes Care 23: 1326-1332

28. LaPorte RE, Orchard TJ, Kuller LH et al. (1981) The Pittsburgh insulin-dependent diabetes mellitus registry: the relationship of insulin-dependent diabetes mellitus incidence to social class. Am J Epidemiol 114: 379-384

29. National Diabetes Data Group (1979) Classification and diagnosis of diabetes mellitus and other categories of glucose intolerance. Diabetes 28: 1039-1057

30. Faas SJ, Menon R, Braun ER, Rudert WA, Trucco M (1996) Sequence-specific priming and exonuclease-released fluorescence detection of HLA-DQB1 alleles. Tissue Antigens 48: 97-112

31. Rudert WA, Braun ER, Jaquin-Gerstl A, Faas SJ, Trucco M (1997) Strategies for synthesis of double-labelled fluorescent oligonucleotide probes for 5' nuclease assay. Biotechniques 22: 140-145

32. Trucco M (1994) Advancements in DNA technology as applied to the study of human histocompatibility complex. In: Dorman JS (eds) Standardization of epidemiologic studies of host susceptibility. Plenum Press, New York, pp 231-240

33. Grubin CE, Daniels T, Toivola B et al. (1994) A novel radiobinding assay to determine diagnostic accuracy of isoform-specific glutamic acid decarboxylase antibodies in childhood IDDM. Diabetologia 37: 344-350

34. Kawasaki E, Eisenbarth GS, Wasmeier C, Hutton JC (1996) Autoantibodies to protein tyrosine phosphataselike proteins in type 1 diabetes: overlapping specificities to phogrin and ICA512/IA-2. Diabetes 45: 1344-1349

35. Pietropaolo M, Peakman M, Pietropaolo SL et al. (1998) Combined analysis of GAD65 and ICA512(IA-2) autoantibodies in organ and non-organ specific autoimmune diseases confers high specificity for insulin-dependent diabetes mellitus. J Autoimmun 11: 1-10

36. Williams AJK, Bingley PJ, Bonifacio E, Palmer JP, Gale EAM (1997) A novel micro-assay for insulin autoantibodies. J Autoimmun 10: 473-478

37. Lipton RB, Atchison J, Dorman JS et al. (1991) Genetic, immunological, and metabolic determinants of risk for type 1 diabetes mellitus in families. Diabet Med 9: 224-232

38. DPT-1 Study Group (1995) The Diabetes Prevention Trialtype 1diabetes (DPT-1): implementation of screening and staging of relatives. Transplant Proc 27: 3377

39. Dib SA, Colman PG, Dotta F, Tautkus M, Rabizadeh A, Eisenbarth GS (1987) Expression of "cytoplasmic" islet cell antigens by rat pancreas. Diabetes 36: 982-985

40. Pilcher C, Elliott RB (1984) Improved sensitivity of islet cell cytoplasmic antibody assay in diabetics. Lancet i: 1352

41. Rewers M, Norris JM, Eisenbarth GS et al. (1996) Betacell autoantibodies in infants and toddlers without IDDM relatives: diabetes autoimmunity study in the young (DAISY). J Autoimmun 9: 405-410

42. Zimmet PZ, Tuomi T, Mackay IR et al. (1994) Latent autoimmune diabetes mellitus in adults (LADA): the role of antibodies to glutamic acid decarboxylase in diagnosis and prediction of insulin dependency. Diabet Med 11: 299-303

43. Turner R, Stratton I, Horton Vet al. (1997) UKPDS 25: autoantibodies to islet-cell cytoplasm and glutamic acid decarboxylase for prediction of insulin requirement in type 2 diabetes. Lancet 350: 1288-1293

44. Pietropaolo M, Barinas-Mitchell E, Pietropaolo SL, Kuller LH, Trucco M (2000) Evidence of islet cell autoimmunity in elderly patients with Type 2 diabetes mellitus. Diabetes 49: $32-38$ 
45. Verge CF, Stenger D, Bonifacio E et al. (1998) Combined use of autoantibodies (IA-2 autoantibody, GAD autoantibody, insulin autoantibody, cytoplasmic islet cell antibodies) in type 1 diabetes: Combinatorial Islet Autoantibody Workshop. Diabetes 47: 1857-1866

46. Rosenbloom AL, Schatz DA, Krischer JP et al. (2000) Therapeutic controversy. Prevention and treatment of diabetes in children. J Clin Endocrinol Metab 85: 494-508

47. Kulmala P, Rahko J, Savola K et al. (2000) Stability of autoantibodies and their relation to genetic and metabolic markers of Type I diabetes in initially unaffected schoolchildren. Diabetologia 43: 457-464

48. Novak EG, Ortqvist E, Nord E et al. (2000) Stability of disease-associated antibody titers in pregnant women with type 1 diabetes with or without residual beta-cell function. Diabetes Care 23: 1019-1021

49. Becker DJ, Libman IM, Pietropaolo M, Dosch HM, Arslanian S, LaPorte RE (2000) Children with obesity and diabetes; Is it type 1 or type 2? J Pediatr Endocrinol Metab 13 [Suppl 4]: 1235

50. Imagawa A, Hanafusa T, Miyagawa J-I, Matzuzawa Y, for the Osaka IDDM Study Group. (2000) A novel subtype of Type 1 diabetes mellitus characterized by rapid onset and absence if diabetes-related antibodies. N Engl J Med 342: 301-307

51. Lernmark $\AA$ (2000) Rapid onset of Type 1 diabetes with pancreatic exocrine dysfunction. N Engl J Med 342: 344-345

52. Winter WE, Maclaren NK, Riley WJ, Clarke DW, Kappy MS, Spillar RP (1987) Maturity-onset diabetes of youth in Black Americans. N Engl J Med 316: 285-291

53. Banerji MA, Chaiken RL, Huey H et al. (1994) GAD antibody negative NIDDM in adult black subjects with diabetic ketoacidosis and increased frequency of human leukocyte antigen DR3 and DR4. Flatbush diabetes. Diabetes 43: 741-745

54. Riley WJ, Maclaren NK, Krischer J et al. (1990) A prospective study of the development of diabetes in relatives of pa- tients with insulin-dependent diabetes. N Engl J Med 323: 1167-1172

55. Bingley PJ, Williams AJK, Gale EAM (1999) Optimized autoantibody-based risk assessment in family members. Implications for future intervention trials. Diabetes Care 22: 1796-1801

56. Kulmala P, Savola K, Petersen JS et al. (1998) Prediction of insulin-dependent diabetes mellitus in siblings of children with diabetes. J Clin Invest 101: 327-336

57. Roep BO (1996) T-cell responses to autoantigens in IDDM. The search for the Holy Grail. Diabetes 45: 1147-1156

58. Luppi P, Zanone MM, Hyoty $\mathrm{H}$ et al. (2000) Restricted TCR $\mathrm{V} \beta$ gene expression and enterovirus infection in Type I diabetes: a pilot study. Diabetologia 43: 1484-1497

59. Lipton RB, Kocova M, LaPorte RE et al. (1992) Autoimmunity and genetic factors contribute to the risk of insulin-dependent diabetes mellitus in families: islet cell antibodies and HLA DQ heterodimers. Am J Epidemiol 136: 503-512

60. Kulmala P, Savola K, Reijonen H et al. (2000) Genetic markers, humoral autoimmunity, and prediction of Type 1 diabetes in siblings of affected children. Diabetes 49: 48-58

61. Peakman M, Tree TI, Endl J, Van Endert P, Atkinson MA, Roep BO (2001) Characterization of preparations of GAD65, proinsulin, and the islet tyrosine phosphatase IA2 for use in detection of autoreactive T-cells in type 1 diabetes: report of phase II of the Second International Immunology of Diabetes Society Workshop for Standardization of T-cell assays in type 1 diabetes. Diabetes 50: 1749-1754

62. Peakman M, Stevens EJ, Lohmann T et al. (2000) Naturally processed and presented epitopes of the islet cell autoantigen IA-2 eluted from HLA-DR4. J Clin Invest 104: $1449-1457$

63. Atkinson M, Honeyman M, Peakman M, Roep B (2000) Tcell markers in Type I diabetes: progress, prospects and realistic expectations. Diabetologia 43: 819-820 